International Journal of Environment, Agriculture and Biotechnology
Vol-6, Issue-3; May-Jun, 2021
J Journal Home Page Available: https://ijeab.com/
Journal DOI: $10.22161 /$ ijeab

Article

Peer-Reviewed Journal

\title{
Detection of mycotoxins from some micro and macro endophytic ascomycetes fungi
}

\author{
Aditi Saini ${ }^{1}$, Vipin Parkash ${ }^{* 1}$, Vineet Kumar ${ }^{2}$, Akshita Gaur ${ }^{1}$, Harsh Chirag ${ }^{1}$
}

${ }^{1}$ Forest Pathology Discipline, Forest Protection Division, Forest Research Institute (Indian Council Forestry Research \& Education, Autonomous Council under Ministry of Environment \& Forests, Government of India), Dehradun-248006, Uttarakhand, India.

${ }^{2}$ Chemistry and Bio-prospecting Division, Forest Research Institute, Dehradun, India

*Corresponding author: bhardwajvpnpark@ rediffmail.com

Received: 15 May 2021; Received in revised form: 07 Jun 2021; Accepted: 15 Jun 2021; Available online: 30 Jun 2021 (C)2021 The Author(s). Published by Infogain Publication. This is an open access article under the CC BY license (https://creativecommons.org/licenses/by/4.0/).

\begin{abstract}
The immense importance of endophytic fungi in industries has attracted the attention of researchers for their chemical and biochemical properties. Some of ascomycetes fungal species like Penicillium, Aspergillus, Neurospora are the novel source of secondary metabolites such as mycotoxins, tannins, alkaloids, terpenoids, etc. Some of the fungal secondary metabolites are useful in pharmaceutical industries for drugs production whereas some mycotoxins are screened to be harmful in most of the cases; hence, it becomes imperative to know the biochemical aspects of wild fungi regarding their usage. This study involves screening of mycotoxins from some endophytic micro ascomycetes fungi e.g. Fusarium solani, Penicillium chrysogenum, Geotrichum candidum (micro fungi) and macro ascomycetes fungi e.g. Xylaria hypoxylon and Daldinia concentrica (macro fungi) through Thin Layer Chromatography (TLC) technique which is a simple physicochemical laboratory procedure and conventional analytical method for quantifying the actual amounts of toxins. In TLC, different solvent systems were used for extrication of compounds/mycotoxins based on their colours. The identification of mycotoxins was done by toning the colours on the TLC plates as per available standard methods and protocols in laboratory. The probable detected and tentatively identified mycotoxins on Thin Layer Chromatographic plates that appeared in different colours were Zearlenone (faint blue), Citrinin (yellow or bright yellow), Aspertoxin (pink), Nivalenon acetate (orange) and Diacetoxiscipenol \& Beauvericin (light brown to brown). This kind of studies can be helpful in categorizing any wild fungal species as toxigenic or non-toxigenic based on their natural occurrence and either edible or inedible in nature. There are also some mycotoxins that possess medicinal properties and some are harmful, thus, this detection can open new outlooks and prospects of new wild fungal source/s of medicinally important compounds/mycotoxins. The future proposal of this study is to further identify the particular mycotoxin/s available in target fungal species by standardizing the isolation and identification through some advance techniques.
\end{abstract}

Keywords-Daldinia concentrica, Fusarium solani, Geotrichum candidum, Penicillium chrysogenum, Thin Layer Chromatography, Xylaria hypoxylon.

\section{INTRODUCTION}

Some ascomycetes fungi are unicellular whilst some are organized to multi-cellular ascocarps that produce spores. Ascomycetes are cosmopolitan in nature generally terrestrial, often found in fresh and tidal zones of marine waters and some are endophytic in nature while some are parasitic on insects and animals, saprophytic and rests are responsible for causing destructive plant diseases (wilts and powdery mildews) [1-2]. Organized fungal hyphae of some ascomycetes fungi produce secondary metabolites such as mycotoxins, tannins, terpenoids, alkaloids, etc. Some of these secondary metabolites are commercially 
utilized in pharmaceutical industry for drugs production and in bio-refineries. For instance, Fusarium, Penicillium and Neurospora are being using as a source of natural pigments with the functionality for food feed and cosmetic application [3]. Goswami et al. [4] reported 'Echinocandins' produced by Aspergillus species which is a new novel class of drugs for fungal infections. Sharmila et al. [5] investigated that Fusarium oxysporum produces Cyclosporin-A which is an immunosuppressant and currently used in the treatment of cancer, organ transplant patients and in the treatment of auto-immune diseases including Acquired Immunodeficiency Syndrome (AIDS). Penicillum and Aspergillus both fungi produce mycotoxins which are used as the wonder drug [6]. However, mycotoxins are screened to be harmful in most cases. Several hundred different mycotoxins have been identified but most commonly observed mycotoxins that present a concern to human health and livestock include aflatoxins, ochratoxin A, patulin, fumonisins, zearalenone and nivalenol/deoxynivalenol [7-9]. Many species of Penicillium can also produce a wide range of toxic compounds such as citrin and citreoviridin [9-11]. Awuchi et al. [12] reported Aflatoxin B1 and B2 (AFB) and Aflatoxin G1 and G2 (AFG); their metabolites include Aflatoxin M1 (AFM1), Aflatoxin M2 (AFM2), Aflatoxicol (AFL) and Aflatoxin Q1 (AFQ1). Aflatoxin B1 is regarded as the most toxic and detected in scantily stored agricultural produce including maize, rice, cassava, cottonseed, millet, sorghum, sesame seeds, sweet corn, chilli peppers, tree nuts, sunflower seeds, spices and wheat. Nielsen et al. [13] found that the mycotoxins ochratoxin A (Aspergillus carbonarius and less frequently A. niger) and fumonisin B2 (A. niger) are the most problematic compounds for human and animal safety point of view. Therefore, it is important to identify the mycotoxins that may help us to categories these fungal species as toxigenic or non-toxigenic and/or either edible or non-edible because some mycotoxins have medicinal uses and some are harmful in nature. There are some following reports in the literature on extraction methods of mycotoxins. Zheng et al. [14] gave an overview for analysis of mycotoxins by rapid methods and conventional analytical methods while Turner et al. [15] also described the analytical methods for determination of mycotoxins. Betina [16] discussed on general technical aspects of thinlayer chromatography of mycotoxins including extraction and clean-up procedures, adsorbents and solvent systems, detection methods, two-dimensional TLC, highperformance TLC (HPTLC), quantization and preparative TLC (PLC). Scott et al. [17] detected mycotoxins by using thin-layer chromatography technique with suitable general solvent systems and only with one initial spraying reagent.
They detected the toxins namely aflatoxins B1, B2, G1, and G2, ochratoxin A, aspertoxin, luteoskyrin, zearalenone, 4-acetamido-4- hydroxy-2-butenoic acid ylactone, diacetoxyscirpenol, and its 8-(3methylbutyryloxy) derivative [T-2 toxin (5)] and nivalenol and its acetate, in addition to several antibiotics now regarded as mycotoxins, namely gliotoxin, citrinin, patulin, penicillic acid and sterigmatocystin. Visible or ultraviolet light was used to visualize the toxins, before and after spraying reagent. These mycotoxins are produced mainly by species of Aspergillus, Penicillium and Fusarium. Hassan et al. [18] worked on Aspergillus species to extract mycotoxins. Similarly, Azliza et al. [19] examined 30 fungal strains which represent 12 Fusarium species i.e. $F$. oxysporum, $F$. solani, $F$. semitectum, $F$. nelsonii, $F$. compactum, $F$. equiseti, $F$. chlamydosporum, $F$. proliferatum, F. subglutinans, F. sacchari, F. lateritium and $F$. incarnatum-equiseti species. These complex isolated from wild grasses in Peninsular Malaysia identified four major mycotoxins i.e. moniliformin (MON), fumonisin B1 (FB1), zearalenone (ZEN) and beauvericin (BEA) using TLC and HPLC techniques. Gerding et al. [20] studied on human urinary mycotoxin excretion patterns in Bangladesh, Germany and Haiti using a rapid and sensitive LC-MS/MS approach. RodríguezCarrasco et al. [21] determined a new analytical method for the rapid detection of ten mycotoxins including patulin, zearalenone and eight trichothecenes (nivalenol, fusarenon-X, diacetoxyscirpenol, 3-acetyl-deoxynivalenol, neosolaniol, deoxynivalenol, T-2 and HT-2) in wheat semolina by using an acetonitrile-based extraction procedure and gas chromatography-tandem mass spectrometry. Although, there are reports available on mycotoxins in food stuffs contaminated by different fungi but there are very few reports on mycotoxins of endophytic micro and wild macro fungi in literature.

Keeping in view all literature review, the present study was aimed to detect the mycotoxins from some endophytic micro ascomycetes fungi e.g. Fusarium solani, Penicillium chrysogenum, Geotrichum candidum and wild macro ascomycetes fungi e.g. Xylaria hypoxylon, Daldinia concentrica and to find whether if there is any difference in mycotoxins occurrence and probable mycotoxins were detected and perceived based on colours obtained in plates through Thin Layer Chromatography.

\section{MATERIALS AND METHODS}

Fresh samples of macro fungi e.g. Xylaria hypoxylon and Daldinia concentrica were collected from adjoining/forest area of Asan River which is located in

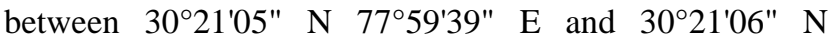


77 $59^{\circ} 37^{\prime \prime E}$ and kept in poly bags and refrigerated whereas the micro endophytic fungal samples of Fusarium solani, Geotrichum candidum, Penicillium chrysogenum were taken and procured from National Type Culture Collection, Forest Research Institute, Dehradun, Uttarakhand, India which were already isolated in the laboratory from the roots of host plant/s under a project $(\mathrm{P}$. no. R\&D/UK-02/2018-19/NMPB-IVA). Culturing of different micro fungal samples e.g. Fusarium solani (AG/C3/1), Geotrichum candidum (AG/C3/2), Penicillium chrysogenum (AG/C3/3) and macro fungal samples e.g. Xylaria hypoxylon (AS/F1), Daldinia concentrica (AS/F2) (endophytic in nature as per review of literature) [29-30], were accomplished again in the laboratory of Pathology Discipline, Forest Research Institute, Dehradun, under aseptic conditions. Sub culturing was done from different cultures to get the pure colony of all micro and macro fungal samples. Mass culturing was facilitated using PDB (Potato Dextrose Broth) as the appropriate growth medium. Pure fungal colonies from prepared sub cultures were inoculated in broth under sterile conditions. Flasks were then incubated for the desired growth of fungi. After incubation of 1-2 weeks, cultures of the preferred fungal samples were acquired.
The identification was facilitated by standard methods and microscopy. The identification of all collected macro fungal samples was done by standard microscopic methods and considering various morphological and anatomical features into account [2226]. Besides these identification keys, some following authentic websites were also browsed for identification.

(http://www.mushroomobserver.org,http://www.mushroo mexpert.com,http://www.rogersmushrooms.com,http://ww w.americanmushrooms.com,http://www.fungiphoto.com)

The glassware used were cleaned with distilled water and ethanol followed by oven drying. Fractionation and Soxhlet methods were used for the extraction of fungal samples. Media was filtered in vacuum distillation unit by which the two components of the media were separated. Separation was carried in two parts of the media i.e. Culture and liquid part. All the fungal samples except Daldinia concentrica got separated out in vacuum filtration but centrifugation was done for 6 minutes at 4250 rpm to separate out the fungal sample of $D$. concentrica. The following Figure 1 shows the map and site of collection along with sporophores of endophytic macro fungi.
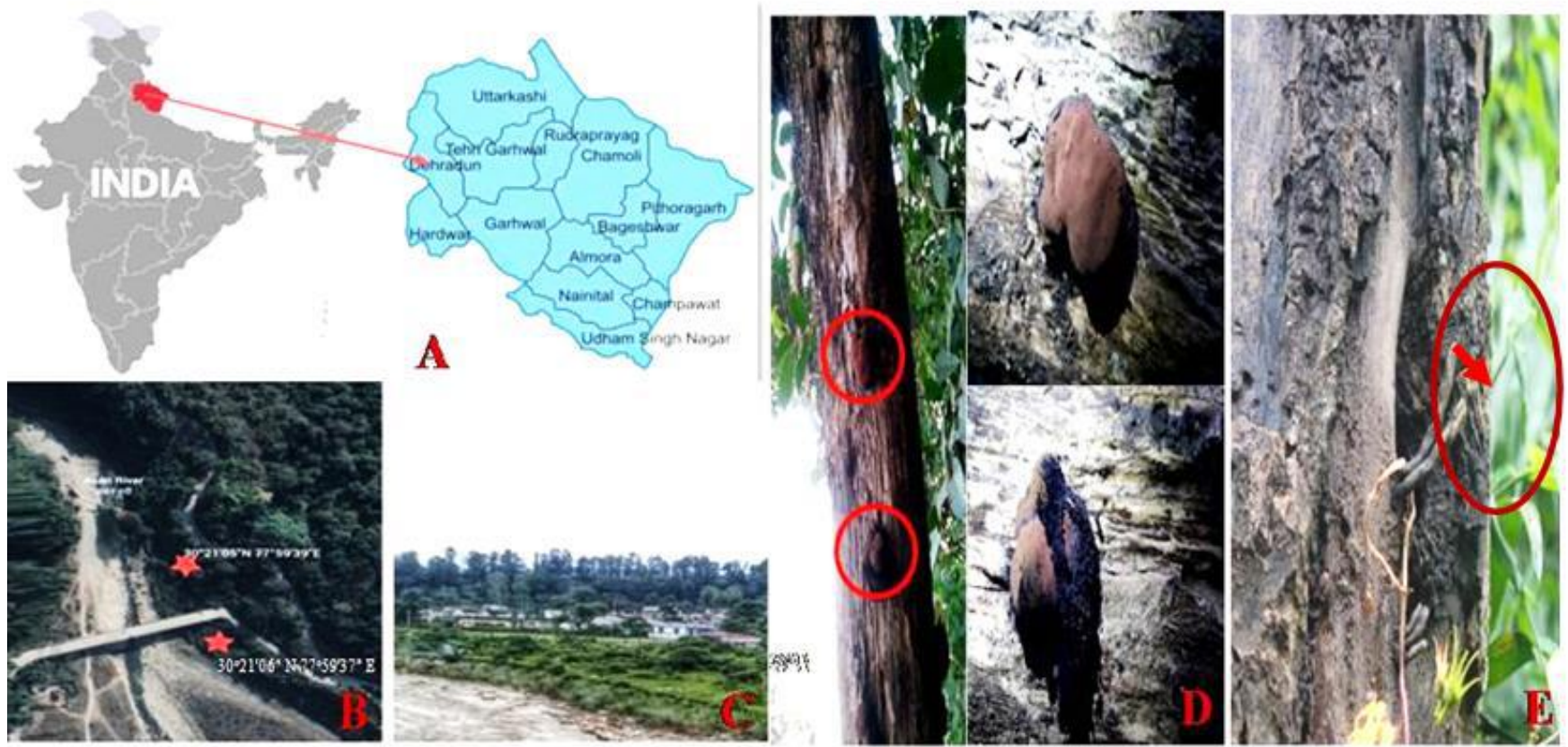

Fig.1: (A) Map of collection site, (B) Satellite image of Tons river flowing through reserve forest, (C) Site of collection, (D) Fruiting bodies of Daldinia concentrica attached to forest tree snag and (E) Fruiting body of Xylaria hypoxylon.

Fractionation-The filtered part was treated with three solvents namely petroleum ether, chloroform and butanol to fractionate the compound present in complex mixture. The media was treated with chemicals according to their polarity. After fractionation the fraction of Petroleum ether, chloroform and butanol were collected in conical flask; 2 tablespoons of anhydrous sodium sulphate were added to remove any trace of water. The samples were then filtered by using fluted filter paper rinsed with solvent before distillation. Distillation was carried out by heating 
and reflux with petroleum ether and chloroform at $75^{\circ} \mathrm{C}$ for 5 hours. The solvent was removed with the help of rotary evaporator to get a concentrated sample [27].

Soxhlet-Fungal mycelium was extracted with chloroform and methanol in 1:1 ratio using a Soxhlet extractor at $60^{\circ} \mathrm{C}$ for 6-8 hours. Extracted solvent washed and then removed by rotary evaporator to get a subsequent amount of extracts [28]. Processed extracts were then used for detecting mycotoxins employing TLC [16].

\section{RESULTS AND DISCUSSION}

The Thin Layer Chromatographic plates were run in different mobile phase/solvents (Table 1) followed by heating at $120^{\circ} \mathrm{C}$ for 30 minutes in hot air oven.

Table 1: Different solvents and spraying reagents used for Thin Layer Chromatography

\begin{tabular}{|c|c|c|c|}
\hline $\begin{array}{c}\text { Fungal } \\
\text { specimens }\end{array}$ & $\begin{array}{c}\text { TLC } \\
\text { Plates }\end{array}$ & Solvents & Spraying Reagents \\
\hline \multicolumn{4}{|c|}{ Endophytic micro fungi } \\
\hline \multirow{3}{*}{$\begin{array}{l}\text { Fusarium } \\
\text { solani }\end{array}$} & (A) & $1.5 \%$ Methanol in Chloroform & $\begin{array}{l}\text { Freshly preprared } \mathrm{p} \text { - } \\
\text { anisaldehyde reagent* }\end{array}$ \\
\hline & (B) & $\begin{array}{l}\text { Benzene Methanol Acetic Acid } \\
(12: 1: 0.5)\end{array}$ & $\begin{array}{l}\text { Freshly preprared p- } \\
\text { anisaldehyde reagent* }\end{array}$ \\
\hline & (C) & $\begin{array}{l}\text { Toluene Ethyl Acetate with Formic Acid } \\
(6: 3: 1)\end{array}$ & $\begin{array}{l}\text { Freshly preprared } \mathrm{p}- \\
\text { anisaldehyde reagent* }\end{array}$ \\
\hline \multirow{3}{*}{$\begin{array}{l}\text { Penicillium } \\
\text { chrysogenum }\end{array}$} & (D) & 4\% Methanol in Chloroform & $5 \%$ Sulphuric Acid \\
\hline & (E) & $3 \%$ Methanol in Chloroform & $\begin{array}{l}\text { Freshly preprared p- } \\
\text { anisaldehyde reagent* }\end{array}$ \\
\hline & $(\mathrm{F})$ & $\begin{array}{l}\text { Toluene Ethyl Acetate with Formic Acid } \\
(6: 3: 1)\end{array}$ & $\begin{array}{l}\text { Freshly preprared } \mathrm{p}- \\
\text { anisaldehyde reagent* }\end{array}$ \\
\hline \multirow{3}{*}{$\begin{array}{l}\text { Geotrichum } \\
\text { candidum }\end{array}$} & (G) & Chloroform Petroleum Ether $(1: 1)$ & $5 \%$ Sulphuric Acid \\
\hline & (H) & $\begin{array}{l}\text { Toluene Ethyl Acetate with Formic Acid } \\
(6: 3: 1)\end{array}$ & $\begin{array}{l}\text { Freshly preprared } \mathrm{p} \text { - } \\
\text { anisaldehyde reagent* }\end{array}$ \\
\hline & (I) & $\begin{array}{l}\text { First, dip in } 10 \% \text { Oxalic Acid and run } 3 \% \\
\text { Methanol in Chloroform }\end{array}$ & $\begin{array}{l}\text { Freshly preprared } \mathrm{p}- \\
\text { anisaldehyde reagent* }\end{array}$ \\
\hline \multicolumn{4}{|c|}{ Endophytic macro fungi } \\
\hline \multirow{3}{*}{$\begin{array}{l}\text { Daldinia } \\
\text { concentrica }\end{array}$} & $(\mathrm{J})$ & 1.5\% Methanol in Chloroform & $\begin{array}{l}\text { Freshly preprared } \mathrm{p} \text { - } \\
\text { anisaldehyde reagent* }\end{array}$ \\
\hline & $(\mathrm{K})$ & $\begin{array}{l}\text { Toulene Ethyl Acetate with Formic Acid } \\
(6: 3: 1)\end{array}$ & $\begin{array}{l}\text { Freshly preprared } \mathrm{p} \text { - } \\
\text { anisaldehyde reagent* }\end{array}$ \\
\hline & (L) & $\begin{array}{l}\text { First, dip in } 10 \% \text { Oxalic acid and run in } 1 \% \\
\text { Methanol in Chloroform }\end{array}$ & $\begin{array}{l}\text { Freshly preprared } \mathrm{p} \text { - } \\
\text { anisaldehyde reagent* }\end{array}$ \\
\hline \multirow{2}{*}{$\begin{array}{l}\text { Xylaria } \\
\text { hypoxylon }\end{array}$} & $(\mathrm{M})$ & $\begin{array}{l}\text { Toluene Ethyl Acetate with Formic Acid } \\
(6: 3: 1)\end{array}$ & $\begin{array}{l}\text { Freshly preprared p- } \\
\text { anisaldehyde reagent* }\end{array}$ \\
\hline & $(\mathrm{N})$ & $\begin{array}{l}\text { Benzene Methanol Acetic Acid } \\
(24: 2: 1)\end{array}$ & $\begin{array}{l}\text { Freshly preprared } \mathrm{p} \text { - } \\
\text { anisaldehyde reagent* }\end{array}$ \\
\hline
\end{tabular}




\begin{tabular}{|l|l|l|l|}
\hline & $(\mathrm{O})$ & $1.5 \%$ Methanol in Chloroform & $\begin{array}{l}\text { Freshly preprared p- } \\
\text { anisaldehyde reagent* }\end{array}$ \\
\hline
\end{tabular}

*p- anisaldehyde reagent (glacial acetic acid, conc. $\mathrm{H}_{2} \mathrm{SO}_{4}$ and p- anisaldehyde)

Culturing of different endophytic micro fungal species namely Fusarium solani, Geotrichum candidum, Penicillium chrysogenum and endophytic macro fungal species e.g. Xylaria hypoxylon, Daldinia concentrica were carried out under aseptic conditions. Sub-culturing was done from different fungal cultures to get the pure colony of all tested fungi. The fungal extracts from the various fungal samples after mass culture were used for the detection of mycotoxins using different methods like fractionation and Soxhlet. The solvents obtained after fractionation and Soxhlet extraction were then concentrated in water bath and rotary distillation resulting in various extracts of different solvents. Thin Layer Chromatography (TLC) was done for detecting mycotoxins. Silica gel plates were used for running of solvents as already stated above (Table-1), the plates were run in different mobile phase/solvents using various spraying reagents. The following Table 2 shows the microscopic characteristics of all micro and macro endophytic fungi.

Table 2: Cultured fungal colony and microscopic characteristic of ascomycetes fungal samples

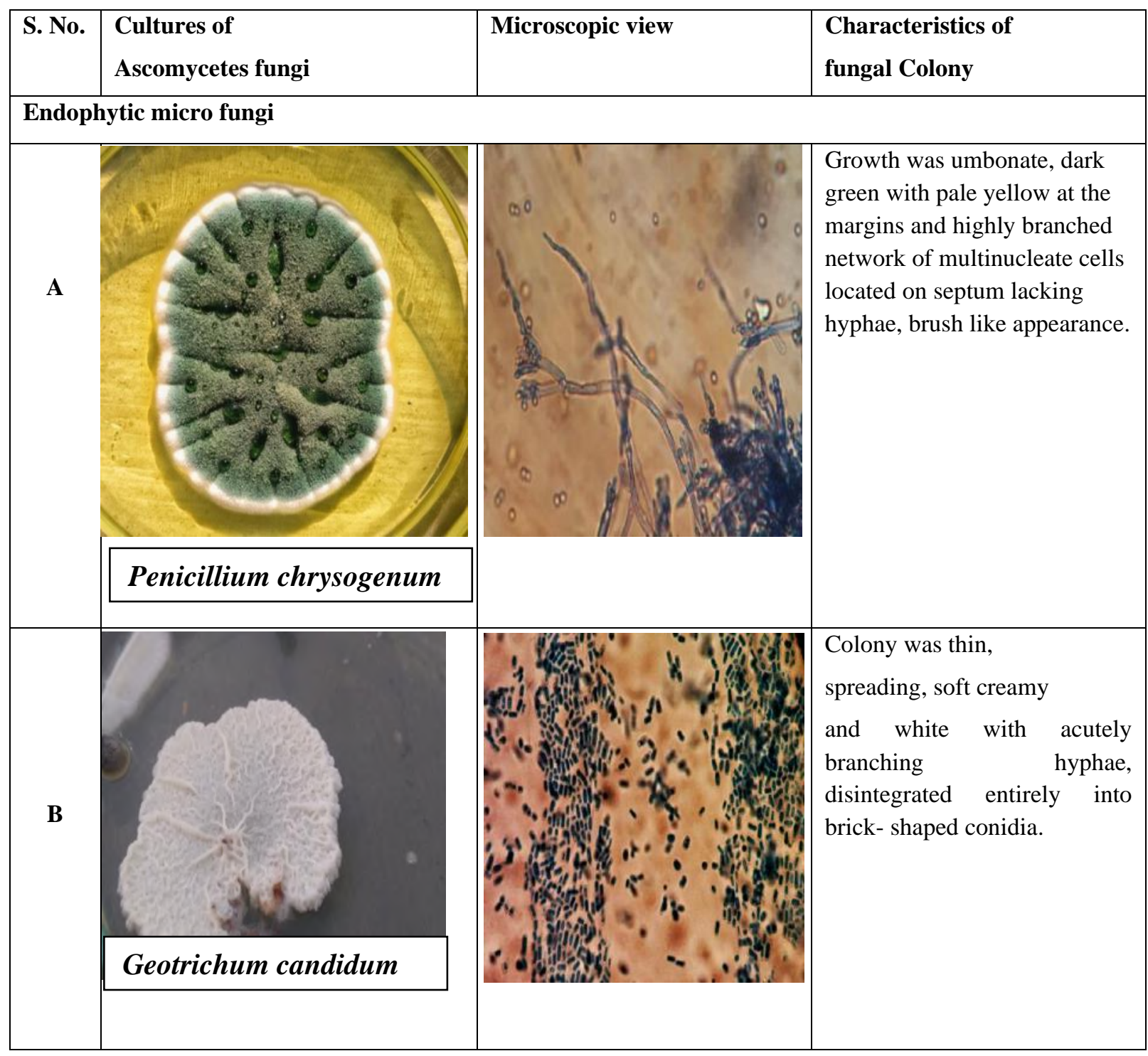




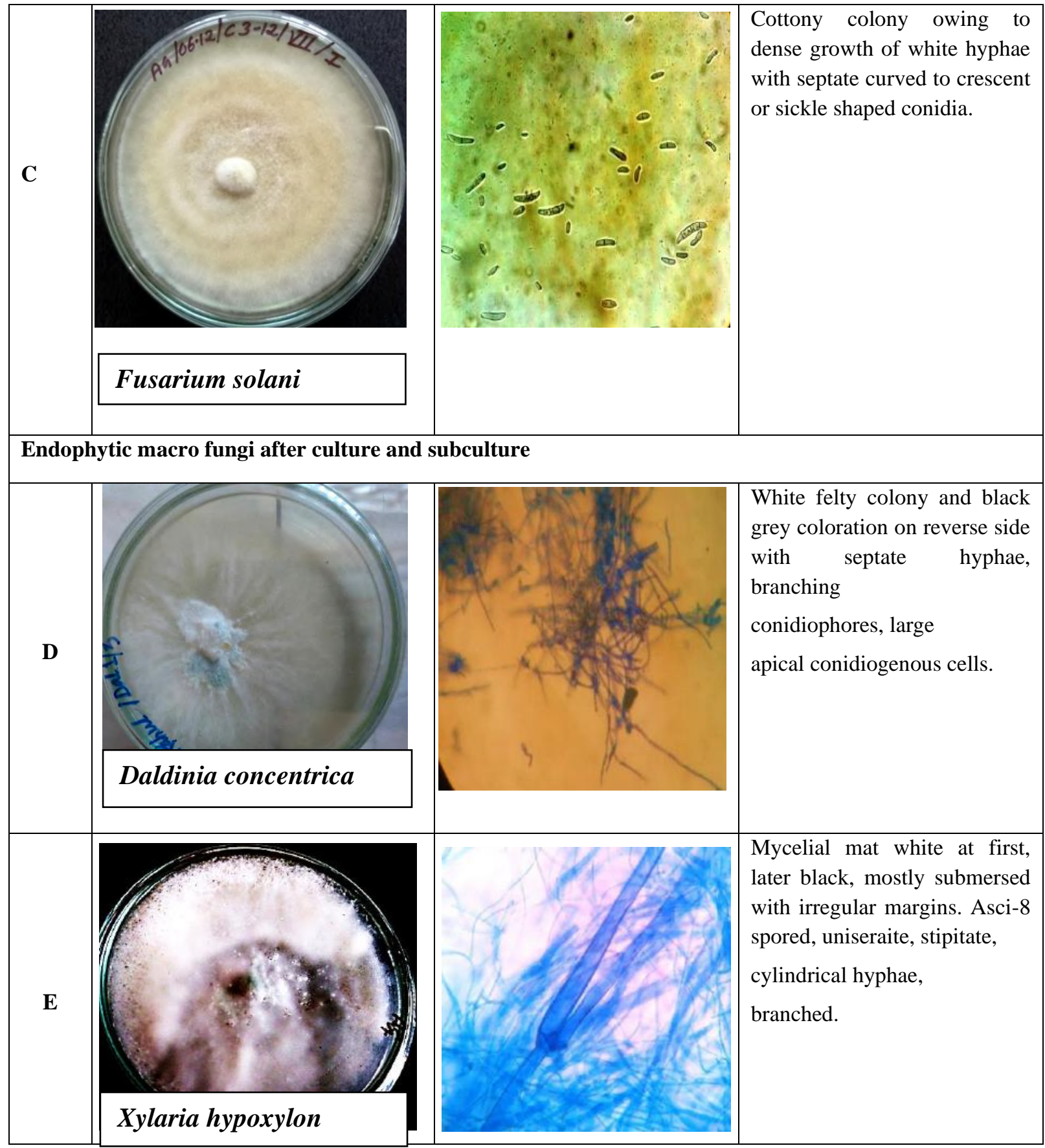

In endophytic micro fungi e.g. Fusarium solani TLC plates (A, B \& C), $1.5 \%$ methanol in chloroform, benzene methanol acetic acid and toluene ethyl acetate with formic acid respectively were used as solvent whereas freshly preprared p-anisaldehyde was taken as visualising reagent. Yellow, faint blue, orange and pink were spotted in TLC plate (A), yellow and faint blue in TLC plate (B), while pink, bright yellow, faint blue, orange and brown were clearly observed in TLC plate (C). In Penicillium chrysogenum TLC plates (D, E \& F), 4\% methanol in chloroform, $3 \%$ methanol in chloroform and toluene ethyl acetate with formic acid were taken as solvents for plates respectively, for visualisation $5 \%$ sulphuric acid was used for TLC plate (D) and freshly preprared p-anisaldehyde was used for TLC plates (E \& F). Prominent colours observed were yellow and pink for TLC plate (D) while yellow and faint blue in TLC plates (E \& F). In Geotrichum candidum, chloroform petroleum ether, toluene ethyl acetate with formic acid were used in TLC plates $(\mathrm{G} \& \mathrm{H})$ respectively, while plate (I) was pre-treated with oxalic acid $(10 \%)$ in methanol was used as solvent to prevent peak from tailing by acidic mycotoxins such as cyclopiazonic acid, penicillic acid, citrinin and ochratoxin A [16]. For visualisation 5\% sulphuric acid was used for plate $(\mathrm{G})$ and freshly preprared p-anisaldehyde reagent was selected for plates (H\&I). Faint blue, yellow and brown 
were the prominent colours spotted in TLC plate $(\mathrm{H})$ whereas no clear separations of colours were seen in TLC plates ( $\mathrm{G} \& \mathrm{I})$ due to low polarity of solvents the spots could not run on the TLC plates. While in case of endophytic macro fungi e.g. Daldinia concentrica, $1.5 \%$ methanol in chloroform, toulene ethyl acetate with formic acid as solvents were used in plates $(\mathrm{J} \& \mathrm{~K})$, while plate (L) was pre-treated with oxalic acid by submersion in $10 \%$ solution of oxalic acid in methanol. Whereas freshly preprared p-anisaldehyde was the spraying reaget. Major colours observed in plates were yellow and faint blue in $(\mathrm{J}$
$\& \mathrm{~K})$ whereas pink, yellow and orange were dominant in TLC plate (L). In case of Xylaria hypoxylon, toluene ethyl acetate with formic acid, benzene methanol acetic acid and methanol in chloroform were taken as solvents in TLC plates ( $\mathrm{M}, \mathrm{N} \& \mathrm{O})$ respectively. For visualisation freshly preprared $\mathrm{p}$-anisaldehyde was used. Yellow, pink and faint blue were the prominent colours observed in TLC plates (M) whereas faint blue and yellow were spotted in TLC plates ( $\mathrm{N} \& \mathrm{O}$ ). The following Figure 2 shows the diffrence of mycotoxin occrrence between endophytic micro and macro fungi.

\section{Illumination of mycotoxins of endophytic micro fungi in TLC plates -}
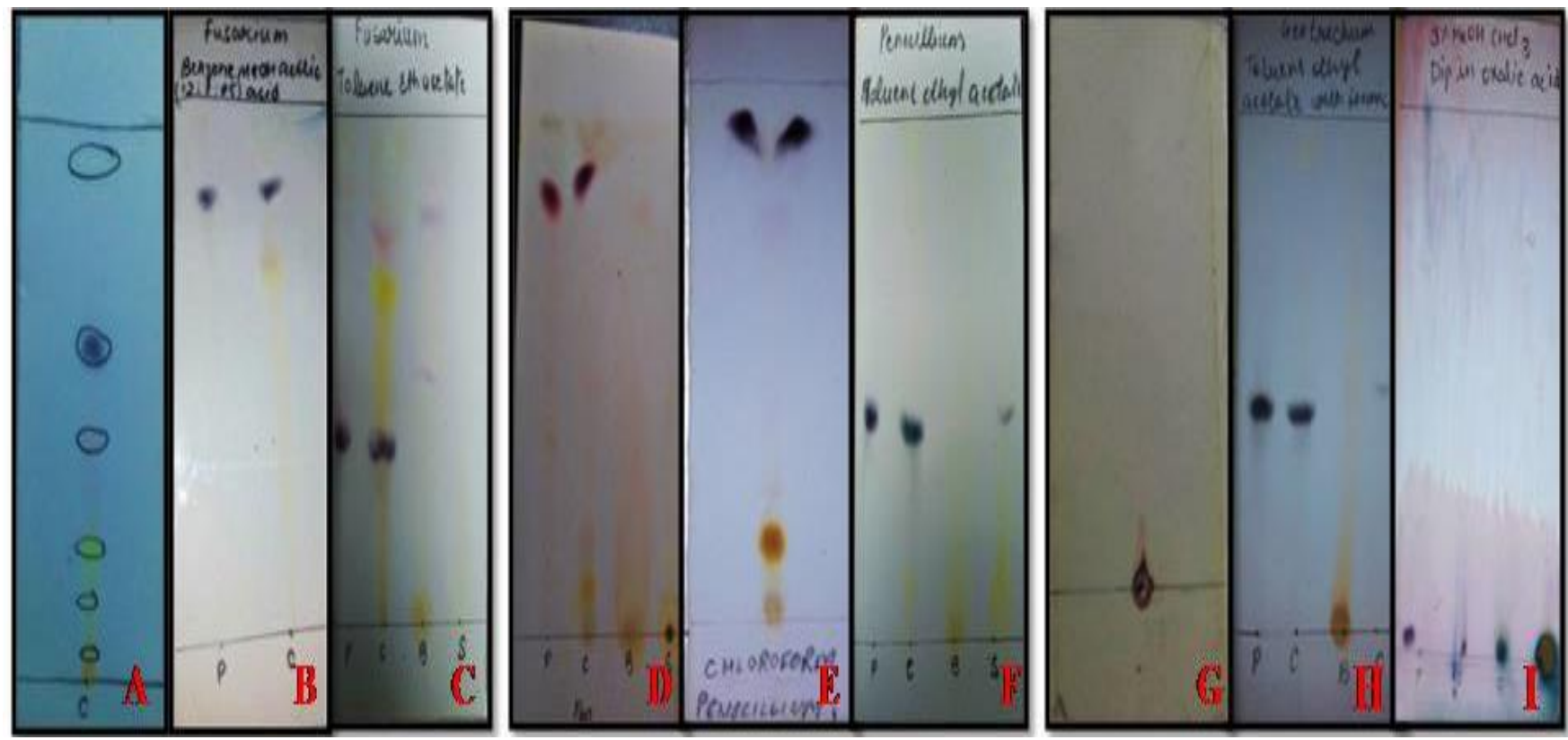

Illumination of mycotoxins of endophytic macro fungi in TLC plates -
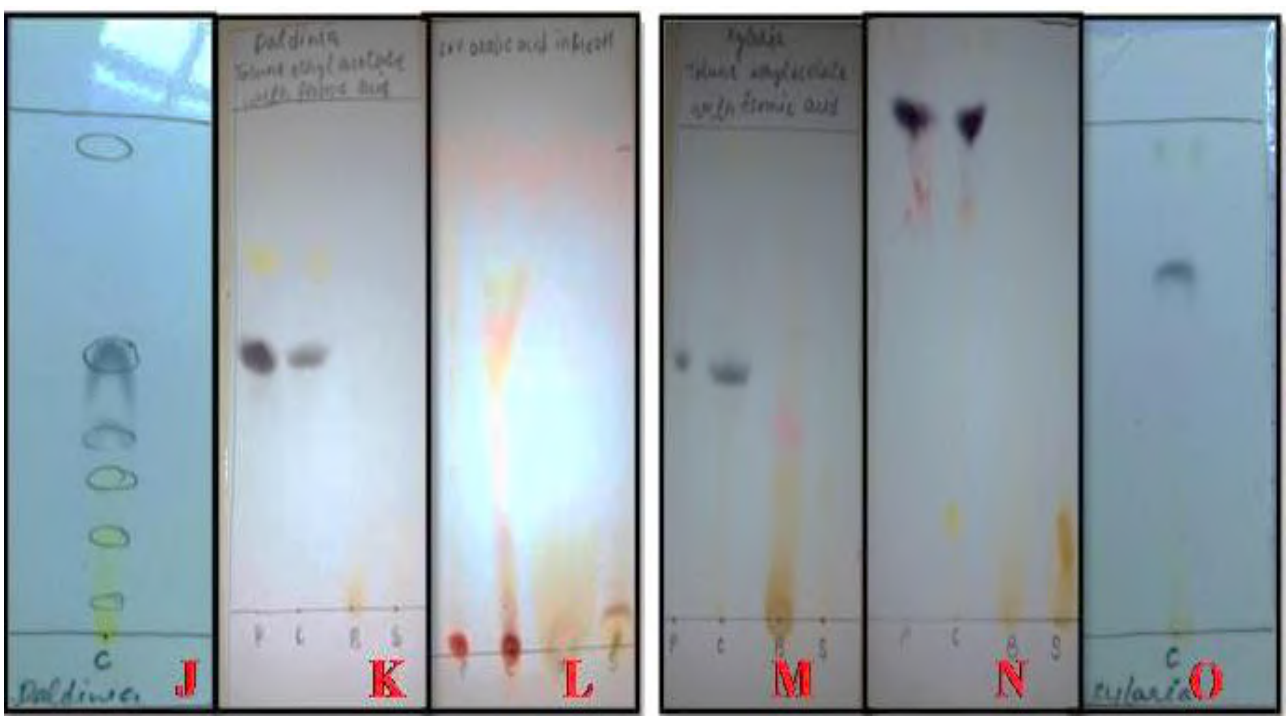

Fig.2: Mycotoxins in different endophytic micro (A-I) and macro (J-O) fungal extracts using Thin Layer Chromatography (TLC) 
All plates were run in different solvent systems, some plates reflected colour whereas some systems were found unsuited for the extracts and thus, no colour was observed. Based on the colour appeared on the TLC plates, detection and tentative identification of all illuminated mycotoxins was done cautiously as per standard key and note available in laboratory [17]. Beauvericin (BEA) was found to be the highest frequency of mycotoxins in Fusarium species, followed by MON, ZEN and FB1 mycotoxins [19]. This study also revealed the presence report of BEA production by $F$. solani. Screening procedure for the detection of mycotoxins used by Scott et al. [17] was referred for further detection and perceived identification of mycotoxins on the basis of colours obtained on the TLC plates in Table 3.

Table 3: Probable mycotoxins based on colours using Thin Layer Chromatography; Scott et al. [17]

\begin{tabular}{|c|c|c|c|}
\hline $\begin{array}{l}\text { Fungal } \\
\text { specimens }\end{array}$ & $\begin{array}{l}\text { TLC } \\
\text { Plates }\end{array}$ & Colours (under visible light) & Probable Mycotoxins in fungal samples \\
\hline \multirow{3}{*}{$\begin{array}{l}\text { Fusarium } \\
\text { solani }\end{array}$} & (A) & $\begin{array}{l}\text { Yellow brown, Faint blue, Orange and } \\
\text { Pink }\end{array}$ & \multirow{3}{*}{$\begin{array}{l}\text { Zearalenone, Citrinin or } \\
\text { Luteoskyrin, } \\
\text { Diacetoxiscirpenol, } \\
\text { Aspertoxin and Nivalenol acetate }\end{array}$} \\
\hline & (B) & Yellow, Faint blue & \\
\hline & (C) & $\begin{array}{l}\text { Yellow, Pink, Bright yellow, Faint } \\
\text { blue, Orange and Brown }\end{array}$ & \\
\hline \multirow{3}{*}{$\begin{array}{l}\text { Penicillium } \\
\text { chrysogenum }\end{array}$} & (D) & Yellow and Pink & \multirow{3}{*}{$\begin{array}{l}\text { Zearalenone, Diacetoxiscirpenol } \\
\text { and Citrinin }\end{array}$} \\
\hline & (E) & Yellow and Faint blue & \\
\hline & (F) & Faint blue and Yellow & \\
\hline \multirow{3}{*}{$\begin{array}{l}\text { Geotrichum } \\
\text { candidum }\end{array}$} & (G) & No separation of colours & \multirow[t]{3}{*}{ Zearalenone, Nivalenol acetate and Citrinin } \\
\hline & (H) & $\begin{array}{l}\text { Faint blue, Yellow } \\
\text { and Brown }\end{array}$ & \\
\hline & (I) & No separation of colours & \\
\hline \multirow{3}{*}{$\begin{array}{l}\text { Daldinia } \\
\text { concentrica }\end{array}$} & (J) & Bright yellow and Faint blue & \multirow{3}{*}{$\begin{array}{l}\text { Zearalenone, Aspertoxin, } \\
\text { Diacetoxiscirpenol and Luteoskyrin }\end{array}$} \\
\hline & $(\mathbf{K})$ & Faint blue and Yellow & \\
\hline & (L) & Pink, Yellow and Orange & \\
\hline \multirow{3}{*}{$\begin{array}{l}\text { Xylaria } \\
\text { hypoxylon }\end{array}$} & (M) & Yellow, Pink and Faint blue & \multirow{3}{*}{$\begin{array}{l}\text { Zearalenone, Citrinin or } \\
\text { Luteoskyrin and Diacetoxiscirpenol }\end{array}$} \\
\hline & $(\mathbf{N})$ & Faint blue and Yellow & \\
\hline & (O) & Faint blue and Yellow & \\
\hline
\end{tabular}

For the confirmation of these mycotoxins some more specific tests have to be done. The colour of mycotoxins may vary for different solvent systems and spraying reagents under ultraviolet light. The further biochemical analysis is under progress.

\section{CONCLUSION}

The wide importance of ascomycetes fungi in medicines and industries attracted our attention towards its chemical and biochemical properties. This study provides an idea about the essential and non-essential biochemical compounds present in different species of the fungi. Mycotoxins are very important metabolites produced by the fungus in their defence against insects and plants. The present study focuses on mycotoxins produced by micro and macro endophytic fungi naturally and for which three micro endophytic fungal species e.g. Fusarium solani, Geotrichum candidum, Penicillium chrysogenum and two macro endophytic fungal species e.g. Xylaria hypoxylon, Daldinia concentrica were selected and tested for the presence of mycotoxins and differences (if any) in them. For the confirmation of mycocompounds/toxins in these chosen wild endophytic fungal species which has never been done before thus, it was the first attempt of its kind to extract and identify mycocompounds/toxins from wild endophytic micro and macro fungi. A basic approach i.e. Thin Layer Chromatography was used for the screening of mycotoxins on the basis of colour obtained on the TLC plates as the purpose was to check the presence or absence of unidentified mycotoxins in the selected wild fungal 
species. Various extracts of the species were taken in different solvents, as mycotoxins were soluble in discrete solvents. Probable mycotoxins were identified on the basis of colours obtained in thin layer chromatography which may help us to categories these fungal species as either toxigenic or non-toxigenic or edible or non-edible (macro fungi) as some mycotoxins have medicinal importance and some are detrimental in nature. The future prospect of this study is to identify the particular mycotoxins available in the target fungal species by standardizing isolation and identification techniques with the help of advanced and sophisticated modern techniques.

\section{ACKNOWLEDGEMENTS}

The corresponding author, Dr. Vipin Parkash is thankful to National Medicinal Plant Board, New Delhi for financial assistance in the project. All the authors are also thankful to the Director, Forest Research Institute (Indian Council of Forestry Research \& Education), Dehradun for facilitating the research activities in laboratories of Forest Pathology Discipline. The authors are thankful to Dr. S. K. Sharma of Himalayan Forest Research Institute, Shimla, Himachal Pradesh, India for providing assistance and guidance in survey work.

\section{REFERENCES}

[1] Carlile MJ, Watkinson SC, Gooday GW. The fungi (2nd ed.), San Diego. CA: Academic. 2001.

[2] Reitz EJ, Shackley M. Viruses, Bacteria, Archaea, Protists, and Fungi. In: Environmental Archaeology. Manuals in Archaeological Method, Theory and Technique, Springer, Boston, MA.2012; 161-189. doi:10.1007/978-1-4614-33392_6

[3] Gmoser R, Ferreira JA, Lennartsson PR, Taherzadeh MJ. Filamentous ascomycetes fungi as a source of natural pigments, Fungal Biology and Biotechnology, 2017; 4:(1), $1-25$.

[4] Goswami S, Rani A, Priyadarshini R, Bhunia B, Mandal T. A Review on production of echinocandins by Aspergillus sp., Journal of Biochemical Technology, 2013; 4 : (1), 568575.

[5] Sharmila K, Thillaimaharani KA, Logesh AR. Production of cyclosporin A by saprophytic filamentous fungus Fusarium oxysporum, Int. J. Pharm. Pharm. Sci.,2012; 4, 149-153.

[6] Egbuta MA, Mwanza M, Babalola OO. A review of the ubiquity of ascomycetes filamentous fungi in relation to their economic and medical importance, Advances in Microbiology, 2016; 6: (14), 1140-1158.

[7] Pitt JI. Toxigenic fungi and mycotoxins, British Medical Bulletin. 2000; 56: (1), 184-192.
[8] Frisvad JC, Thrane U, Samson RA, and Pitt, JI. Important mycotoxins and the fungi which produce them, Advances in Food Mycology, 2006; 3-31.

[9] Richard JL. Some major mycotoxins and their mycotoxicoses-An overview, International Journal of Food Microbiology, 2007; 119 :( 1-2),3-10.

[10] Adeyeye SA. Fungal mycotoxins in foods: A review, Cogent Food \& Agriculture, 2016; 2: (1), 1213127.

[11] Barbosa TS, Pereyra CM, Soleiro CA, Dias EO, Oliveira AA, Keller KM, Rosa CA. Mycobiota and mycotoxins present in finished fish feeds from farms in the Rio de Janeiro State, Brazil, International Aquatic Research, 2013; 5:(1),1-9.

[12] Awuchi CG, Amagwula IO, Priya P, Kumar R, Yezdani U, and Khan MG. Aflatoxins in foods and feeds: A review on health implications, detection, and control, Bull. Env. Pharmacol. Life Sci., 2020; 9: 149-155.

[13] Nielsen KF, Mogensen JM, Johansen M, Larsen TO, and Frisvad JC. Review of secondary metabolites and mycotoxins from the Aspergillus niger group. Bioanalytical Chemistry, 2009; 395:(5), 1225-1242.

[14] Zheng MZ, Richard JL, Binder J. A review of rapid methods for the analysis of mycotoxins, Mycopathologia, 2006; 161: (5), 261-273.

[15] Turner NW, Subrahmanyam S, Piletsky SA. Analytical methods for determination of mycotoxins: a review, Analytica Chimica Acta., 2009; 632: (2), 168-180.

[16] Betina, V. Thin-layer chromatography of mycotoxins, Journal of Chromatography A, 1985; 334, 211-276. https://doi.org/10.1016/S0021-9673 (00)80272-1.

[17] Scott PM, Lawrence JW, Van Walbeek W. Detection of mycotoxins by thin-layer chromatography: application to screening of fungal extracts, Applied Microbiology, 1970; 20: (5), 839p.

[18] Hassan G, Bullerman LB. Aspergillus flavus and Aspergillus parasiticus: Aflatoxigenic fungi of concern in foods and feeds: A review, Journal of Food protection, 1995; 58: (12), 1395-1404. https://doi.org/10.4315/0362028X-58.12.1395

[19] Azliza IN, Hafizi R, Nurhazrati M, Salleh B. Production of major mycotoxins by Fusarium species isolated from wild grasses in Peninsular Malaysia, SainsMalays, 2014; 43, 8994.

[20] Gerding J, Ali N, Schwartzbord J, Cramer B, Brown DL, Degen GH, Humpf HU. A comparative study of the human urinary mycotoxin excretion patterns in Bangladesh, Germany, and Haiti using a rapid and sensitive LC-MS/MS approach, Mycotoxin Research, 2015; 31:(3), 127-136.

[21] Rodríguez-Carrasco Y, Berrada H, Font G, Mañes J. Multimycotoxin analysis in wheat semolina using an acetonitrilebased extraction procedure and gas chromatographytandem mass spectrometry, Journal of Chromatography A, $2012 ; 1270$, 28-40 https://doi.org/10.1016/j.chroma.2012.10.061

[22] Smith AH. The mushroom hunter's field guide, University of Michigan Press, Annarbor. 1963; 67pp.

[23] Miller OK. Mushrooms of North America. 1997 New York, E.P. Dutton. 
[24] Kaul TN. Introduction to Mushroom Science (systematic), Oxford and B.H. Publ. Co. Pvt. Ltd., New Delhi,1997; $198 \mathrm{p}$.

[25] Smith AH, Smith HV, Weber NS. How to know the gilled mushrooms, Wm. C. Brown Co. Dubuque. 1979; 334pp.

[26] Coetzee JC. Taxonomic notes on the Clathraceae (Phallales: Phallomycetidae) sensu Bottomley and a new key to the species in Southern Africa, Bothalia. 2010; 40: (2), 155-159.

[27] Pudziuvelyte L, Jakštas V, Ivanauskas, L. LaukevičienėA, IbeCFD, Kursvietiene L, Bernatoniene J. Different extraction methods for phenolic and volatile compounds recovery from Elsholtziaciliata fresh and dried herbal materials, Industrial Crops and Products, 2018; 120: 286294.

[28] Yang L, Jiang JG, Li WF, Chen J, Wang DY, Zhu L. Optimum extraction process of polyphenols from the bark of Phyllanthus emblica L. based on the response surface methodology, Journal of Separation Science, 2009; 32:(9), 1437-1444.

[29] Liarzi O, Bar E, Lewinsohn E, Ezra D. Use of the endophytic fungus Daldinia cf. concentrica and its volatiles as bio-control agents, PLoS One. 2016; 11; (12), e0168242. doi:10.1371/journal.pone.0168242

[30] Petrini L, Petrini O. Xylariaceous fungi as endophytes, Sydowia. 1985; 38: 216-234.

\section{Websites consulted and retrieved during the study period-}

[31] www.mushroomobserver.org

[32] www.mushroomexpert.com

[33] www.rogersmushrooms.com

[34] http://americanmushrooms.com

[35] http://www.fungiphoto.com 